\title{
Pinteresque Dialogue in the Interrogation Scene of "The Birthday Party"
}

\author{
By Nashwa Elyamany*
}

\begin{abstract}
Pinter's outstanding contributions to modern theatre afford a new layer of dramatic discourse, characteristically coined as Pinteresque discourse, in which power games evolve. In the interrogation scene of his first full-length three-act play, The Birthday Party, all the characters are portrayed in constant verbal struggle for survival and domination. In this paper, the researcher reports on a multi-faceted analysis of three randomly selected excerpts of the scene. The proposed framework for the study, which focuses attention on language in use, is drawn from conversation analysis and a two-fold pragmatic analysis. The conversation analysis, in terms of the dominant systematics of turn-taking prevalent in the scene, yields significant findings in regard to the characterization and the themes continually perpetuated by the play text. The pragmatic analysis sheds light on how flouting the Gricean maxims and manipulating different impoliteness super strategies on the part of the characters encompass asymmetrical relational power amongst them. This, in turn, gives rise to an "identity loss" of those stripped of power, by virtue of unwarranted and excessive verbal assault on their face. The study calls for a performance-based analysis of dramatic discourse to account for a full understanding of the wide array of dialogic and stylistic features and dynamics prevalent in audio-visual representations.
\end{abstract}

Keywords: Conversational Implicatures, Gricean Maxims, Identity Loss, Impoliteness Theory, Power, Social Distance

\section{Introduction}

The emergence of the Theatre of the Absurd, which encompasses the plays of the 1950s and 1960s, is one of the prominent movements that thrived in the literary world. The new genre communicated post-war conditions and the negative effects of the World Wars on people's frame of mind using a multitude of unique styles. One pertinent characteristic of the theatre is incongruity, or odd talk, infused in the dramatic dialogue as an embodiment of the inherent depression, seclusion, insecurity, uncertainty, and anxiety of mankind (Esslin 1968, Carter and McRae 2001).

Harold Pinter (1930-2008) is one of the defining playwrights of the movement and the 2005 Nobel Prize laureate in literature. More specifically, the play texts of Pinter unravel a new dimension in this European theatre genre. He disentangles the pitfalls and apprehension disrupting the social life of postwar time. His outstanding contributions to modern theatre afford a new layer of dramatic discourse that is exclusive, innovative, and influential, characteristically coined as Pinteresque discourse, in which power games evolve. Like other absurd playwrights, Pinter explores a plethora of themes, namely unknown menace, verbal torture, power struggle for domination, and mental disorder (Esslin 1970, 1982, Gale 1977).

*Head of Languages Department, Arab Academy for Science, Technology and Maritime Transport (AASTMT), Egypt. 
Brevity is a key feature of Pinteresque dialogue that naturally gives rise to multiple shades of meaning. As such, Pinter's audiences never reach the exact meaning of the cryptic play texts. Rather, they tend to draw several interpretations out of them and none of these interpretations is inherently variant. In Pinteresque drama, language is distinctively manipulated by a small cohort of characters engaged in a power game to drive the theme of power struggle across to the audience's mind. In a nutshell, Pinter places emphasis on the futility and absurdity of human existence, the incongruity of relationships among people, the struggle for power, and the lack of communication as a natural consequence.

\section{The Birthday Party: The Interrogation Scene and Absurdity}

The Birthday Party (1958) is a vivid manifest of Pinter's dramatic innovations pertinent to the impossibility of verification and the mystification of reality in the late fifties and sixties. It is the first play that exhibits, in its full-length three-act texture, the features that set Pinter apart from his Absurdist forerunners. The play is a dramatized game of power in miniature, in which manipulative language serves as a tool for establishing asymmetrical relations among the characters. Pinter's play focuses on the life of Stanley Webber, a retired pianist in his late thirties, living in idle seclusion in a closed room in a boarding house, castaway from the outside world.

In Pinteresque terms, the closed room occupied by a small cohort of absurd people clustering inside at the mercy of one another, not engaging in any communicative dialogue, is note-worthy. A lack of explicit detail concerning character and events typifies Pinteresque dialogue. Characters are bizarrely motionless and static, when compared to their counterparts in almost any other style of dramatic presentation. Such a portrayal is a vivid manifestation of the post-war individual's dilemma: man's search for existential security and quest for a safe haven in a world saturated with apprehension, terror and tremor, and lack of genuine communication (Esslin 1970: 23). In order for the absurd characters to reveal the predicament of man's existential security, the tripartite of mystery, menace, and humor intermingle in the mixing bowl of Pinter's play text.

Indeed, the interrogation scene is one of The Birthday Party's most thoughtprovoking absurd scenes. Apparently, Stanley is in self-exile, seeking refuge away from a past indefinite episode in his life - an episode that banished him into seclusion. The monotonous life at the boarding house is what Stanley is in dire need of, to preserve his seclusion. Unexpectedly, the relatively serene ambiance is disrupted by the intrusion of two agents of some unidentified association, Goldberg and McCann, who come to claim Stanley. Stanley is subsequently subjected to a ridiculously bizarre cross-examination by the two visitors throughout a birthday party that finally dissolves into a series of aggressive acts.

Goldberg and McCann's interrogation of Stanley is an exemplar of comedy of menace. In a matter of a ferocious few minutes of stage time, Stanley witnesses a bombardment of brutal accusations and gunfire questions. In the context of the interrogation, Pinter deploys stichomythia, a variety of dramatic dialogue whereby 
Goldberg and McCann alternate in shooting Stanley with fairly legitimate questions that soon fall into a surreal mirage of ridiculousness, all of which lack intelligibility. Both strategies intensify Stanley's paranoia, laying the foundation for his imminent breakdown toward the end of Act II. Using language as a weapon, the two men disturb what is invariable in Stanley's life. Stanley, like postwar mankind, is apprehensive of what lies beyond the precincts of his cozy milieu, which is unreceptive and hostile.

\section{Aim of the Analysis}

A careful and thorough study of dramatic discourse as "social interaction" is no easy mission due to the multiple conversational and pragmatic features that inevitably interplay and lend themselves for analysis. Dialogic interaction is not merely linguistic; other non-linguistic variables (the spatio-temporal setting, the roles assumed by the characters and their relational power and rank extremity, the multi-layered speech itself, etc.) synchronize and moderate the dramatic dialogue. The present analysis is within the purview of this thought.

Several studies have dealt with linguistic politeness in dramatic discourse and pertinent critical issues (examples to cite are Bennison 2002, Leech 1992, Simpson 1989). Although theories of politeness, in the literature to date, have shed light on how communicative acts are deployed to sustain harmony in social interactions, very few studies have been carried out on the communicative acts that bring about disharmony in social interactions. In this regard, the researcher endeavors to consider the notion of impoliteness and discusses contextual factors associated with impoliteness, namely the dominant systematics of turn-taking and conversational implicatures. The current study aims to explore how a) the nonobservance of the cooperative principle (Grice 1968, 1975) and b) the manipulation of different impoliteness super-strategies (Culpeper 1996, 2002, 2005, Culpeper et al. 2003) orchestrate to encode asymmetrical power relations among characters.

\section{Research Questions}

The study aims to answer the following research questions:

1. What are the dominant systematics of turn-taking in the three extracts of the interrogation scene under study? What purpose do they serve?

2. Why do Goldberg and McCann flout the Gricean maxims in the three extracts of the interrogation scene under study?

3. What impoliteness super-strategies Goldberg and McCann use in the three extracts of the interrogation scene under study? What purpose do they serve? 


\section{Theoretical Framework}

\section{Conversation Analysis}

In broad terms, the aim of conversation analysis is to reveal the structures of talk that produce and reproduce pattern of social action. Drama is a multi-input dialogue, whereby turn taking and turn allocation strategies among the characters matter. These strategies are managed in a way that mitigates the threat of speech chaos when several participants have the full rights to speak and take turns in interactional contexts. One central conversation analysis concept is "preference". Naturally, at certain points in conversation, certain types of utterances are more favored than others. For instance, the socially preferred response to an invitation is acceptance, not rejection. Sacks et al. (1978), describe the systematic properties involved in turn-taking and turn management in ordinary conversation. Some conversational features which conversation analysis focuses on include openings and closings of conversations; adjacency pairs (e.g. greeting-greeting, complimentcompliment response); topic management and topic shift; conversational repairs; showing agreement and disagreement; introducing bad news and processes of trouble-telling; and mechanisms of turn-taking (Jaworski and Coupland 1999: 20).

\section{The Cooperative Principle and the Gricean Maxims}

In ordinary conversations, what is meant often goes beyond what is said, and this additional meaning is implied and predictable. For non-literal meaning to be transmitted and understood, interactants must collaboratively adhere to numerous "pragmatic" rules, make numerous inferences, and use implicit information over the course of interlocutory exchanges given that indirect non-literal language constitutes a large part of the communicative process (Coulthard 1977, Grice 1968, 1975, Sabbagh 1999, Searle 1975, Sperber and Wilson 1981). There are many nuances in the communication of non-literal language, much of which can be elegantly accounted for in the descriptive work of Grice and Searle. Among Grice's most important contributions to the understanding of communication is his formulation of the Cooperative Principle (henceforth CP).

Grice's CP and its four associated maxims are considered a major contribution to the area of pragmatics, which not only plays an indispensable role in the generation of conversational implications, but also is a successful example showing how human communication is governed by the principle. According to Grice (1975), linguistic exchanges are characteristically cooperative efforts; each participant recognizes in them, to some extent, a common purpose or set of purposes, or at least a mutually accepted direction. The essence of this principle is that communicative partners work together to share information in an exchange as adequately as possible by observing a set of communicative constituent maxims.

These maxims are grouped into four categories unified by particular themes (Grice 1975). The categories include: quantity, i.e., a speaker should give only as much information as is required for a specific exchange; quality, i.e., a speaker should impart only information that is truthful and that can be substantiated; 
relation, i.e., a speaker should only share information relevant to the topic in discussion; and manner, i.e., a speaker should express information in a perspicuous fashion. According to Grice, speakers transfer cohesive messages to listeners either by judiciously observing the maxims or by purposefully flouting them.

$\mathrm{CP}$ is particularly important in the interrogation script of The Birthday Party (1985) because many of the statements are sarcastic with additional meaning. In The Birthday Party, as in many other Pinter plays, language manages to defy its role as a vehicle for communication. What is conveyed between characters is very often detached almost entirely from the actual words that are spoken by them. Pinter takes the language of everyday mundane speech, and parodies it, making a seemingly domestic drama into something much more sinister and humorous. Pinter gives his actors an extraordinary degree of potential to convey various nuances in sound and delivery of lines, thus giving a great wealth of interpretations when enacted on stage.

\section{Conversational Implicatures}

The non-observance of the maxims is of interest while studying meaning that is not conveyed on a direct level. Following the maxims should result in the efficient exchange of literal information between interlocutors (Grice 1975). This is in contrast to the messages projected by speakers who intentionally flout the maxims despite abiding by the CP. In this fashion, speakers impart information beyond the literal meaning of a particular excerpt of discourse, and listeners arrive at the intended meaning through conversational implicature (Grice 1975). Conversational implicatures are pragmatic inferences. Unlike entailments and presuppositions, they are not tied to the particular words and phrases in an utterance but arise instead from contextual factors and the understanding that conventions are observed in conversation.

The conversational implicature that is added when flouting is not intended to deceive the recipient of the conversation, but the purpose is to make the recipient look for other meaning (Thomas 1995). Flouting a maxim also signals to the hearer that the speaker is not observing the CP (Cruse 2000). There can be some difficulty understanding flouts since the process itself does not intend to give a justification or an explanation for the flouting (Cruse 2000). As such, listeners derive both the literal meaning and, more importantly, the underlying significance of a spoken message by determining the reasons behind the maxim violations (Grice 1975). To achieve the conversational implicature, the listener must make use of acquired pragmatic knowledge, or knowledge of how language is used in particular contexts, to recognize the reasons for the speaker's maxim breaches, thereby permitting non-literal language forms to be successfully used in communication (Grice 1975). Examples of such language forms include, but are not limited to, irony, metaphor, and hyperbole (Grice 1975). 
Irony

The terms sarcasm and irony are often used interchangeably, and the existing theories of sarcasm are often labeled as theories of irony. The interpretation of verbal irony involves conversational implicature due to the fact that the literal meaning of the words employed by the ironic speaker is often counterfactual and does not, by definition, constitute the intended message. In addition, the notion that indirect language serves important functions in communication also applies to verbal irony as it plays a number of roles in exchanges between speakers and listeners (Ching 1999, Colston 1997, Colston and O'Brien 2000a, 2000b, Dews et al. 1995, Gibbs and Izett 2005, Pexman and Zvaigne 2004).

Specifically, irony can be defined as a negative critical attitude expressed to mock and show disapproval for disagreeable persons or events (Jorgensen 1996, Kreuz and Glucksberg 1989, Lee and Katz 1998). Sarcastic or ironic statements can also be described in reference to levels of politeness and criticism depending on the surface form of the statement. Listeners perceive sarcastic compliments as less polite and as more mocking than direct compliments, which is in contrast to the fact that listeners view sarcastic insults as more mocking and more polite than direct insults (Pexman and Olineck 2002). Listeners are also inclined to consider sarcastic remarks less threatening and more polite than overtly critical statements (e.g., Dews et al. 1995, Jorgensen 1996, Kumon-Nakamura et al. 1995).

Alternately, speakers also employ ironic utterances to emphasize the critical nature of their intended messages (Colston 1997). Apart from conveying various degrees of politeness and criticism, irony appears to be used as an expression of humour (of a malicious variety) because it enhances hyperbolic propositions in communication (Colston and O'Brien 2000b). Of all these functions, the most common purpose of sarcasm for which there is empirical evidence is to express negative criticism in an indirect manner (Colston 1997, Colston and O'Brien 2000a, 2000b, Jorgensen 1996, Kreuz and Glucksberg 1989, Kreuz et al. 1991, Kumon-Nakamura et al. 1995, Lee and Katz 1998, Pexman and Olineck 2002).

\section{Culpeper's Impoliteness Model}

The basic notion of Brown and Levinson's Politeness Theory $(1978,1987)$ can be traced back in Goffman's (1967) concept of "face". In their framework, face consists of two related aspects: negative face (wanting your actions not to be constrained or inhibited by others) and positive face (the positive consistent selfimage that people have and their desire to be appreciated and approved of at least by some other people). Life would be wonderful if our faces remained un-assailed. However, even in relatively mundane interactions, one's actions often threaten the other person's face. For example, requests typically threaten negative face; criticism typically threatens positive face. Acts such as these are called Face Threatening Acts (henceforth FTAs).

Among scholars who worked on impoliteness are Bousfield, Mills, Kasper, Beebe, Keinpointner, Holmes, and Cashman. However, Culpeper's theories have received the most attention (Culpeper 1996, 2002). Culpeper identifies impoliteness 
as "the parasite of politeness" and his model of impoliteness was initially introduced as a parallel to Brown and Levinson's theory of politeness. Culpeper (1996, 2002) refers impoliteness to communicative strategies used to attack face, and thereby create social disruption. For a successful impoliteness, the speaker's intention to offend or threaten the face must be perceived by the hearer (Bousfield 2008, Culpeper et al. 2003). Accordingly, how face threatening any particular act is depends upon a number of factors, but in particular (a) the relationship between the participants and (b) the size of the imposition involved in the act to be performed (Culpeper 2002: 84). Culpeper connects power with the use of impoliteness. In unequal relationships, the person who has more power can be more impolite than the weaker person. The powerful person uses impoliteness to limit the other person's reaction and to threaten him or her with retaliation if he or she acts impolitely. In addition, the existing conflict of interest between the participants causes a particular concern to purposefully attack the addressee's face.

Culpeper's (1996, 2002, 2005, 2010) impoliteness super-strategies, which are systematically related to the degree of face threat from the least to the highest, can be summed up as follows:

1. Bald on record is the most obvious and straightforward impoliteness used when there is much face at stake, and when there is an intention on the part of the speaker to attack the face of the hearer.

2. Positive impoliteness involves the use of strategies designed to damage the recipient's positive face wants. Examples include: "excluding the other from the activity", "using inappropriate identity markers", "using obscure or secretive language", "using taboo words", "calling the other names", etc.

3. Negative impoliteness is deployed to damage the recipient's negative face wants, such as "frighten", "condescend", "scorn or ridicule", "invade the other's space", "explicitly associate the other with a negative aspect", etc.

4. Sarcasm or mock politeness is a face-threatening act performed with the use of politeness strategies that are obviously insincere. The FTA is performed indirectly by means of implicature and these indirect impoliteness strategies may be denied if required.

5. Withhold politeness takes place when the speaker keeps silent when politeness is expected in order to damage the hearer's face (i.e. the absence of politeness work where it would be expected). For example, failing to thank somebody for a present may be taken as deliberate impoliteness.

In dramatic discourse, impoliteness, as a form of aggression, is particularly interesting to examine since it generates the disharmony and conflict between characters, which, in turn, stimulates the interest of audiences and often moves the plot forward. Thus, the aim of this paper is to investigate impoliteness superstrategies, strategies that are embedded to cause offence and social disruption in dramatic dialogue.

In light of the aforementioned account, the researcher analyzes the discourse of three characters (Goldberg, McCann, and Stanley) in three extracts randomly selected from the interrogation scene of The Birthday Party (1958) following a 
multi-layered analytical approach. To show the procedures under which Stanley's identity is lost, a brief, yet insightful conversational analysis is instantiated, followed by a detailed pragmatic analysis with special regard to the nonobservance of the Cooperative Principle (and the flouting of the four maxims) as well as Culpepper's impoliteness super-strategies.

\section{Analysis}

Evidently, an integral part of the menace that lies beyond the surface-level normality of Pinter's play text is the incongruence between the dramatic dialogue and the actions taking place, on the one hand, and the chaotic, emotional, and brutal world beneath them, on the other. The linguistic absurdity prevalent in The Birthday Party may well be suggestive of how absurd the human condition is. Through dramatic dialogue, Pinter parades the inadequacy of the language people use in everyday speech, how language per se has become insufficient, defective, and manipulative.

The nature of language and dialogue is pivotal to the theme of menace in The Birthday Party. The dramatic image of Pinter's play rests on the individual's search for a safe haven in a menacing world saturated with agitation, fear, and miscommunication. When Stanley, the protagonist, learns of the two men's arrival and stay in the boarding house his initial reaction is one of tremor and terror of what is unfamiliar. The play moves from equilibrium to disequilibrium then back to equilibrium; the interrogation scene acts as the catalyst for the transformation of Stanley.

In total, the interrogation runs for more than 150 turns. To facilitate the analysis, the three excerpts under study and the corresponding turns are given numbers for ease of reference (See Appendix A).

\section{Conversational Analysis}

Discourse in The Birthday Party is prized for how tactfully it fosters a deeper perception of the metaphorical anguish of human existence. Terror is intensified with the arrival of the Goldberg-McCann alliance that starts the interrogation and cross-examination. The topic of the three extracts is "interrogation", however, the manner in which it is managed is quite bizarre from start to finish. All characters engage in subterfuge, through their articulated language and calculated silence, combatting with other characters, themselves, and audiences. In their use of a presumably authoritative, naturalistic dramatic language whose literal significance is consistently replete with interpolations of metaphor, Goldberg and McCann proceed with the investigation.

Goldberg and McCann's role as Stanley's interrogators positions them as visible and aggressive agents of normalization within society. This applies especially during Stanley's interrogation when Goldberg has Stanley's glasses taken away. By blinding their target, Goldberg places both himself and McCann in a position above Stanley by making him become dependent on them in his 
moment of blindness. Stanley remains speechless. His silence only stresses the disintegration of the human personality. In this process, words serve as weapons. Stanley is virtually brainwashed through a series of incomprehensible questions.

How speech is orderly organized in a given play text, as dictated by the dramatist who is in full control, is a reflection of the turn allocations patterns the dramatis personae are licensed to follow. The "one-speaker-speaks-at-a-time" floor management and the turn taking and allocation strategies that help to craft it are the canonical form of speech organization in dramatic texts. This classical mode fosters a context that permits characters to allocate turns to one another. In the interrogation scene, however, the Goldberg-McCann alliance creates a twoversus-one configuration and their participant selection strategy violates the canonical systematics of turn-taking. What follows is an examination of the dominant turn taking techniques that are worthy of scrutiny, namely: topic control and management; turn allocation and turn-taking patterns; adjacency pairs; and repair mechanisms (silence, pauses, etc).

The conversational analysis of the interrogation scene unravels the structure of the three extracts, which is mostly the same. In attempt to control the topic and hold the floor, most of the turns in the three 20-turn extracts belong to the interrogators who act as one unity. In Extracts 1 and 2, only five minimal turns belong to Stanley, and in extract \#3 Stanley produces only two turns, one of them is an unfinished utterance and the second is a scream (See Appendix A). Interestingly, Goldberg is always the center of attention whereas McCann assumes the more passive position and tries to remain out of the way. This allows both figures to play to their strengths given Goldberg's preference for delivering charismatic speeches. It is this lack of speaking skills happens to be McCann's weakness which he is able compensate for by administering physical punishment as well as other actions in order to isolate Stanley from his source of comfort and confidence. During the interrogation scene, topic control and management serve as a vehicle that curtails Stanley's contribution, on the one hand, and modulates the power assumed by Goldberg and McCann, on the other.

On a related note, an exquisite turn-allocation and turn-taking pattern runs across the three extracts. The two interlocutors dominating the scene alternate turns between them like an opera duet; hence they grant each other rights to the floor by virtue of allocating almost equal turns to one another. That is, one turn produced by one interlocutor entices the other to add his own conversational contribution, except for the first extract when Goldberg dominates the floor for a longer while. Goldberg and McCann start off the interrogation by bringing up bizarre topics, which implicates absurdity and confusion (e.g. recognition of external forces, chicken-egg account, etc.). The unusual starts are mandated by the genre of the play to perpetuate the overarching themes it underlies - that of absurdity. In all the three excerpts, Goldberg and McCann proceed by opting for a sequence of FTAs, all meant to exercise power over Stanley in an impolite manner. Intervening instances of repetition of utterances such as "Do you recognize an external force?", "He's sweating", and "Which came first?" suggest voidness and breakdowns in communication. 
In all extracts of the interrogation scene, particularly Extract \#3, the audience's expectation of adjacency pairs (request-response) is not fulfilled. In fact, in their quest for bombarding Stanley with assertions and questions, rapid turns are alternated between Goldberg and McCann. Being minimally included in the dialogue, Stanley is the only disadvantaged character in the scene. It is noteworthy that all turns perform direct FTAs that are menacing and torturing on both psychological and mental levels. No instances of repair mechanisms, overlaps, hesitations, hedges, interruptions, pauses, or moments of silence are discernible. This is deliberate to intensify the power of the two over Stanley. The pattern dominating the extracts highlights the two-interrogator power over the victimized Stanley. As such, Stanley is deprived of the right to answer except for a few incomplete adjacency pairs. Figuratively speaking, when Goldberg and McCann reduce Stanley to silence, they commit a form of murder.

The conversational analysis displays the characteristics of the absurdity and futility of mankind - a typical recurrent theme of the Theater of the Absurd - and pinpoints how dramatic discourse is manipulated as a vehicle to manifest power relations. From what the audience is given about McCann, his primary focus at all times is the completion of the task at hand, which makes him a perfect companion for the dominating Goldberg who seems to thrive when placed in a position of power. However, McCann's desire for efficiency within the mission does not mean that he is a zealot like his partner. The character that undergoes feelings of menace, fear and insecurity (i.e. Stanley) is fully aware of the two visitors' domination and power over him.

Pinteresque dialogue celebrates the use of silence and pauses are effective media of communication - a signature distinctive of almost all Pinter's play texts. Although Stanley's speaking rights are projected during the interrogation, Goldberg or McCann removes these rights instantaneously. The visitors' play of turn order squeezes him out. As their demeaning utterances pile up, their discourse about him manufactures a Webber figure that is helpless to rebut. Metaphorically speaking, Stanley is dead at the end of the scene.

\section{Pragmatic Analysis}

\section{$\underline{\text { The cooperative principle and flouting Grice's maxims }}$}

In the interrogation scene, Pinter manipulates the narrative structure of the dramatic dialogue and fuses the past and the present. Although characters speak in a scene of present reality of a seemingly shared historical past, they play out remembered scenes within the present frame; in other words, Pinter provides no dramaturgical signal of a flashback, but merely represents the past as real and as immediate as the present. In accordance with the $\mathrm{CP}$, there should be conversational contributions at the discourse level among interlocutors as required by the purpose and direction of the interrogation scene. Nevertheless, this is not actualized in the three extracts under study.

Goldberg and McCann purposefully flout the maxims in the course of their talk with Stanley. Although the maxims are violated at the discourse level of what 
is said, the audience is entitled to assume that the maxims, and the overall $\mathrm{CP}$, are observed at the level of what is implicated. As a result, conversational implicatures render the seemingly absurd communication deeper interpretations. Interestingly, absurdity is often linked with humor, and throughout this discourse of incongruity, the audience is challenged to work out reasons for absurdity and is likely to come up with various interpretations.

In The Birthday Party, speech acts are performed to serve the intention of the characters (i.e. assuming power). The interlocutors' direct and indirect threats and insults are masked by a variety of direct speech acts, all of which indicate relational power positions. The three excerpts are vivid manifestations of how the non-observance of the $\mathrm{CP}$, by means of flouting the constituent four maxims in the three-character interaction, serves characterization and the themes perpetuated by the play. Numerous conversational implicatures are generated from flouting the maxims of quantity, quality, manner, and relation. What follows is a detailed account of the manner in which the four maxims are flouted (hence generating conversational implicatures) and the purpose flouting serves.

\section{Flouting the maxim of quantity: over-informativeness}

Goldberg and McCann's contribution in the three dialogues is striking. It is in excess given the length of the extracts in relation to the whole interrogation scene that runs for more than 150 turns. In Extracts \#1 and 2, for instance, all fifteen turns of Goldberg and McCann are gunfire alternating FTAs (See Appendix A). The number of FTAs performed in each of the three extracts is so shocking that the audience is confused as to what sort of horrendous past crimes or sins Stanley is accused of. In essence, all the utterances flout the maxim of quantity.

In pursuit of dominating the floor, the interlocutors heavily rely on excessive and successive FTAs to: first, perpetuate their assumed power over Stanley; second, serve the themes of confusion, futility, and miscommunication. The speech acts performed by the two are mostly declaratives, commissives, interrogatives, and directives in order for them to take the floor and assume power. Their offensive remarks not only damage Stanley's positive and negative face wants but are inherently confusing as well. Although declaratives, for instance, are meant to be informative, the interrogators' utterances are far from that. They are mostly short, abrupt, and nonsensical turns carrying no conceivable meaning of any relevance to the interrogation. The dialogue is outwardly conversational; however, discourse suggests a deeper turmoil than the characters mean to express. Pinter strips the dialogue of logic, sense, or order to reinforce the sinister, torturous intent of the speakers. The intentional deviation from communication relates to the theme of the absurdity of human existence.

Flouting the quality maxim: sarcasm and linguistic metaphors

Instances of flouting the quality maxim are traceable in Extracts \# 1 and 2. Goldberg, McCann, and the audience know quite well that Stanley is not literally "a washout", "a plague", "an odour", or "dead". These remarks are systematic, 
intentional, and non-reciprocal and the conversation continues in spite of the linguistic mockery; Stanley cannot escape the conversation. Although these attributes to Stanley are false at the level of what is said, there is hidden evidence for what they claim, which, in turn, renders conversational implicatures.

Reference to "Drogheda" and the act of betrayal implicates that Stanley has committed a serious crime or sin that he must be arrested and probably executed for. Alternately, Goldberg and McCann employ sarcastic utterances to emphasize the critical nature of their intended messages. Such demeaning and impolite sarcastic remarks and insults (guised by linguistic metaphors) mock the very existence of Stanley. It is noteworthy how these sarcastic remarks and metaphors are escalating as the interrogation progresses. Reducing Stanley's identity to "a washout", "a plague", "an odour" to be finally assumed as "dead" evokes fear of death at the very core of Stanley. This eventually leads to the loss of his identity. The audience works out several interpretations and neither interpretation is more sophisticated or more far-fetched than the other.

\section{Flouting the maxims of relation and manner (ambiguity/obscurity)}

The dramatic dialogue in the three extracts is made up of tedious repetitions as well as contradictions. Goldberg and McCann's utterances are a composite of distorted clichés, ironic utterances, and linguistic metaphors irrelevant to the proceedings of a real-life interrogation (See Appendix A). Language is manipulated for stylistic purposes and, in this sense, the interlocutors deliberately produce ambiguous, obscure, and non-succinct utterances. For instance, the nonsensical reference to chicken and egg, and which came first, implies a breakdown in communication and the absurdity of the dialogue given the fact that this extract is retrieved from an interrogation scene. Though Pinter does not detail Stanley's past, Stanley's behavior during these exchanges suggests some sin or crime - which is his very existence (Table 1).

In the three dialogic extracts, the interrogators, particularly Goldberg, communicates information that goes above and beyond what is strictly said. Hyperbole and verbal irony are co-deployed to give rise to conversational implicatures. Despite the sheer fact that the preliminary reaction to the play is that of incomprehension and bafflement, audiences capture failures to fulfill maxims, calculate implicatures generated by the characters and grasp deeper subtexts in a play in the same way they do with real people in real conversations. They successfully resolve whether in the context of this particular genre of discourse and this particular time and culture the failures or flouts are significant, and make further inferences. The play's appeal is based on numerous instances of irreverent verbal anarchy. 
Table 1. Examples of Flouting the Maxims of Manner

\begin{tabular}{|c|c|}
\hline Extract No. & Examples \\
\hline One & $\begin{array}{l}\text { (Turns 5, 7,9, and } 11 \text { by Goldberg) } \\
\text { Why are you wasting everybody's time, Webber? Why are you getting in } \\
\text { everybody's way? } \\
\text { I'm telling you, Webber. You're a washout. Why are you getting on } \\
\text { everybody's wick? Why are you driving that old lady off her conk? } \\
\text { Why do you behave so badly, Webber? Why do you force that old man out to } \\
\text { play chess? } \\
\text { Why do you treat that young lady like a leper? She's not the leper, Webber! }\end{array}$ \\
\hline Two & 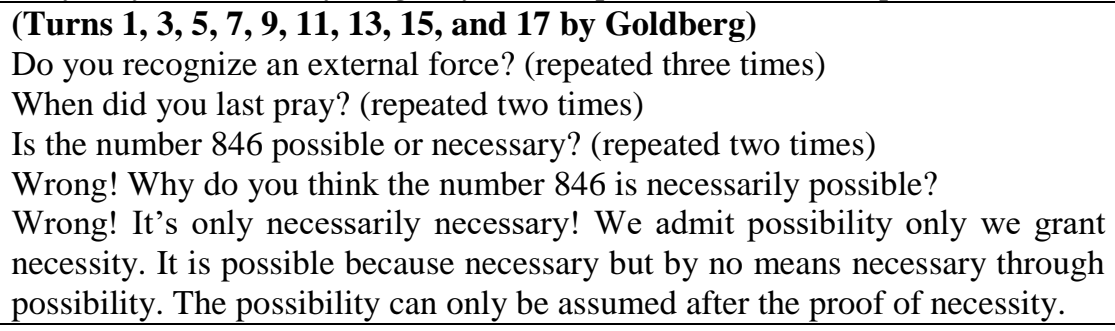 \\
\hline Three & $\begin{array}{l}\text { (Turns } 1,4,6,8,10,12,14,16, \text { and } 20 \text { by Goldberg) } \\
\text { Why did the chicken cross the road? } \\
\text { Which came first? } \\
\text { Which came first? Which came first? Which came first? } \\
\text { He doesn't know. Do you know your own face? } \\
\text { You're a plague, Webber. You're an overthrow. } \\
\text { But we've got the answer for you. We can sterilise you. } \\
\text { Your bite is dead. Only your pong is left. } \\
\text { You betray our breed. } \\
\text { You're dead. You can't live, you can't think, you can't love. You're dead. } \\
\text { You're a plague gone bad. There is no juice in you. You're nothing but an } \\
\text { odour! }\end{array}$ \\
\hline
\end{tabular}

Ironically, in The Birthday Party Pinter manipulates what is seemingly an impartially undramatic, realistic setting to hide a surplus of guilt. The theme of atonement runs throughout the play. Stanley's past is never detailed, yet he is unmistakably a guilty man. Pinter still allows audiences enough visual and aural cues to puzzle out what is happening. Still, beneath this scene's realistic façade is the threat of a more unsettling experience. As such, audiences decipher the messages behind excessive FTAs, menace, insecurity, and desire for power. The questions and accusations brought up by Goldberg and McCann can never be answered: no verifiable factual information about them can be deduced. That they are raised at all is part of the menace: since Stanley's answers (should he offer any) cannot be verified, the answers themselves are not what Goldberg and McCann seek here; rather they seek to force Stanley to undergo the questioning as part of the process of making "a new man" of him.

In a comedy of menace, characters speak and act in a manner that contradicts the expectation of audiences. Hence, spectators are obliged to reassess their perceptions and weigh them against the action currently observed. In other words, audiences are encouraged to draw on several conversational implicatures. Some of these implicatures that are likely to be generated are Goldberg and McCann are people of high relational power, rank, and imposition; Goldberg and McCann are potential prosecutors on account of the verbally aggressive FTAs they perform and 
alternate; Stanley has committed a horrendous crime; Stanley's existence is pointless; and Stanley's tragic end is imminent.

\section{$\underline{\text { Impoliteness analysis }}$}

Impoliteness is an inherently prominent feature of the interrogation scene, which relates to characterization. During the interrogation, Goldberg and McCann draw on a spectrum of impoliteness strategies, hence emphasizing the impact of power relations on dramatic discourse. In fact, impoliteness and its interplay with power manifest themselves in the various strategies employed by the interrogators to assert power over the weakest character in the scene (i.e. Stanley).

Several contextual factors contribute to the understanding of impoliteness as being accidental or intentional. In the three-character, stripped-of-politeness interaction, it is evident that the level of power of the two interlocutors is dependent on the context (the interrogation), the role of the participants in the interaction (Goldberg and McCann being potential prosecutors), the ensuing rights and obligations between them (the right of arresting Stanley) and the response of the addressee (submission to them). In the three extracts, Goldberg and McCann monopolize the conversation using several impoliteness super-strategies in their menacing discourse to attach Stanley's face, namely bald on record impoliteness, sarcasm or mock impoliteness and negative impoliteness. In effect, the characters aim to deliver deeper subtexts in order for the audience to comprehend that real communication takes place underneath the spoken words. This, in turn, gives birth to an entertaining conflict that serves in the construction of characters and advancement of the plot.

A recurrent pattern runs in all the three extracts. Each extract begins with Goldberg asking a series of questions - i.e. negative impoliteness strategies threatening Stanley's negative face (Table 2).

Table 2. Questions as a Negative Impoliteness Super-Strategy

\begin{tabular}{|l|l|}
\hline Extract No. & Examples \\
& $\begin{array}{l}\text { Turn (1) Webber, what were you doing yesterday? } \\
\text { Turn (5) Why are you wasting everybody's time, Webber? Why are you } \\
\text { getting in everybody's way? } \\
\text { Turn (7) Why are you getting on everybody's wick? Why are you driving } \\
\text { that old lady off her conk? } \\
\text { Turn (9) Why do you behave so badly, Webber? Why do you force that old } \\
\text { man out to play chess? } \\
\text { Turn (11) Why do you treat that young lady like a leper? She's not the leper, } \\
\text { Webber! }\end{array}$ \\
\hline \multirow{3}{*}{ Extract \#2 } & $\begin{array}{l}\text { Turns (1), (3) and (5) Do you recognize an external force? } \\
\text { Turns (7) and (9) When did you last pray? } \\
\text { Turns (11) and (13) Is the number 846 possible or necessary? }\end{array}$ \\
\hline \multirow{2}{*}{ Extract \#3 } & $\begin{array}{l}\text { Turn (1) Why did the chicken cross the road? } \\
\text { Turns (4) and (6) Which came first? } \\
\text { Turn (8) Do you know your own face? }\end{array}$ \\
\hline
\end{tabular}

These questions are followed either by irrational offensive accusations such as turns 5, 7, 9, 11, and 17 by Goldberg in Extract \#1 and turns 15 and 16 
by McCann and Goldberg respectively in Extract \#3 or offensive remarks as exemplified in turns 7 and 9 by Goldberg and turns 8 and 9 by McCann in Extract \#2 (Table 3).

Table 3. Examples of Offensive Accusations and Remarks

\section{Extract \#1 \\ Goldberg:}

-Why are you wasting everybody's time, Webber? Why are you getting in everybody's way?

-I'm telling you, Webber. You're a washout. Why are you getting on everybody's wick? Why are you driving that old lady off her conk?

-Why do you behave so badly, Webber? Why do you force that old man out to play chess?

-Why do you treat that young lady like a leper? She's not the leper, Webber!

-You hurt me, Webber. You're playing a dirty game.

Extract \#2

Goldberg: When did you last pray?

McCann: He's sweating!

Extract \#3

McCann: You betrayed our land.

Goldberg: You betray our breed.

In addition to the questions, accusations, and offensive remarks that attack Stanley's negative face, using insults such as "You're a plague, Webber. You are an overthrow. You're what's left!" in Extract \#3 Goldberg and McCann employ bald-on-record impoliteness strategies and threaten Stanley in a bald manner, which fortifies their verbal assault. In these emotionally torturing utterances, there is much face at stake. Stanley is bombarded by a series of questions and assertions that damage his positive and negative face wants. Stanley is being called names, given inappropriate identities, frightened, scorned, ridiculed, and associated with negative aspects. All of which are deliberated to encode asymmetrical power relations, hence bring him to submission.

Pinter is especially fond of building rhythmic crescendos. The dialogue increases in volume, pace, and pitch until it reaches a peak, usually of terror. Goldberg and McCann's excessive verbal attacks on the face of those deprived of (i.e. Stanley) are striking, embedding that notion of "the more powerful the two interlocutors, the more inherently impolite the utterances are". In such an unequal power relation, impoliteness strategies limit Stanley's reactions, leaving him behind in the conversation making no defensive (or offensive) counter attacks except for an intervening scream indicating an imminent nervous breakdown. Stanley's silence is indicative; it is a sign of accepting the impoliteness, a way of searching for proper answers, or a lack of confidence on his part on account of the gunfire consecutive insults directed at him.

Despite the fact that the relationship between the interlocutors is a mystery to the audience, the menacing discourse offers only oblique clues as to why Goldberg and McCann feel entitled to perform FTAs impolitely at various degrees by virtue of their rank. Hence, both level of power and rank extremity grant them the right to use FTAs with varying degrees of impoliteness. Along the same lines, the conversation between the three interlocutors indicate that they are so familiar with each other that there is very low, if any, social distance between them. The interrogators address Stanley by either his first or last name, using no courtesy 
titles. Consistent with Brown and Levinson's Politeness theory, the lower the social distance is among interlocutors, the less the politeness they tend to show.

On a related note, Goldberg seems to be the mastermind who initiates the conversation for McCann to follow. One phrase spoken by Goldberg excites McCann to add his own turn, and it continues like an opera duet. The alternating turns of the two show that Goldberg is of a higher rank and power level that McCann is. Accordingly, more FTAs with higher levels of impoliteness and aggression are performed by Goldberg in this short dialogic extract. However, the sheer fact that both of them collaborate in making this conversation happen indicates no social distance between them. As a natural result of cruel and constant face attacks on Stanley's face, he loses his identity and is transformed into a figure that is unable to say even one word.

Impoliteness strategies not only serve characterization, but they also advance the plot and further the themes that the play underlies (i.e. desire for power, menace, and fear). The three elements of "power of the speaker", "social distance between the interlocutors", and rank extremity (degree of imposition) are at work mandating the performance of FTAs. In The Birthday Party it is not the external violence that happens to Stanley that Pinter aims to portray. Rather, it is the deepest horror of the no place to go and the profoundest desire to be left alone. Clearly, part of the menace, which lies behind the surface normality of Pinter's set, is the incongruence between the dialogue and actions on the one hand and the chaotic, emotional, violent world beneath them on the other.

\section{Conclusion}

The interrogation scene of The Birthday Party is a reflection on, and an allegory of, the existential predicament of mankind. Language is used to show the limitation of communication on account of the lack of genuine connection among human beings, the lack of security, and desire for power.

In the selected excerpts of the interrogation scene, the multi-dimensional analysis highlights two major points. First, language is manipulated at the discourse level to perpetuate the themes of The Birthday Party. Conversational strategies, namely topic management, turn taking techniques, and lack of adjacency pairs reinforces such themes and helps advance characterization as well. Second, on the pragmatic level, the in-depth analysis of how the CP is not observed and the four maxims are flouted (hence creating conversational implicatures) lays out how power relations result in discourse manipulation and embarkation on a spectrum of impoliteness strategies. The study argues that pragmatic tools, namely impoliteness super-strategies and cooperative maxims, are applicable to literary discourse to account for a variety of dynamics of direct relevance to the relational power, social distance, and interactive role of the characters.

The two-pronged comedy of menace positions Pinteresque dialogue within the context of dictatorship, victimization, torture, and brutality. Pinter's investment in revealing the cruelty of the everyday becomes a key to reading the interactions 
between characters. Power emerges in Pinteresque discourse and nobody can escape the network of power relations.

\section{Implications for Future Research}

Future research endeavors can take into account a performance-based analysis of The Birthday Party in light of Martin and White's (2005) Appraisal Theory, Lakoff and Johnson's (2003) Conceptual Metaphor Theory, and Kress and van Leuween's (2006) Visual Design in the theatrical performances and screenplays. The trio of analytical frameworks is likely to pinpoint how audiences are led, by means of well-orchestrated semiotic resources, to reach certain interpretations (rather than others) in relation to language and power in these audio-visual representations.

\section{References}

Bennison N (2002) Accessing character through conversation. In J Culpeper, M Short, P Verdonk (Eds.), Exploring the Language of Drama: From Text to Context, 67-82. New York: Routledge.

Bousfield D (2008) Impoliteness in Interaction. Amsterdam: John Benjamins Publication Company.

Brown P, Levinson S (1978) Universals in language usage: politeness phenomena. In EN Goody (Eds.), Questions and politeness, 56-311. Cambridge: Cambridge University Press.

Brown P, Levinson S (1987) Politeness: Some Universals in Language Usage. Cambridge: Cambridge University Press.

Carter R, McRae J (2001) The Routledge History of Literature in English. London and New York: Psychology Press.

Ching, MKL (1999) Verbal irony against an antagonist. Metaphor and Symbol 14(2): 139147.

Colston HL (1997) "I've never heard anything like it": Overstatement, understatement, and irony. Metaphor and Symbol 12(1):43-58.

Colston HL, O'Brien J (2000a) Contrast and pragmatics in figurative language: Anything understatement can do, irony can do better. Journal of Pragmatics 32(11) :15571583.

Colston HL, O'Brien J (2000b) Contrast of kind versus contrast of magnitude: The pragmatic accomplishments of irony and hyperbole. Discourse Processes 30(2):179199.

Coulthard M (1977) An Introduction to Discourse Analysis. Hong Kong: Longman Group.

Culpeper J (1996) Towards an anatomy of impoliteness. Journal of Pragmatics 25(3): 349-367.

Culpeper J (2002) Impoliteness in dramatic dialogue. In J Culpeper, M Short, P Verdonk (Eds.), Exploring the Language of Drama: From Text to Context, 67-82. New York: Routledge.

Culpeper J (2005) Impoliteness and entertainment in the television quiz show: The Weakest Link. Journal of Politeness Research: Language, Behavior, Culture 1(1): 35-72. 
Culpeper J (2010) Conventionalised impoliteness formulae. Journal of Pragmatics 42(12): 3232-3245.

Culpeper J, Bousfield D, Wichmann A (2003) Impoliteness revisited: With special reference to dynamic and prosodic aspects. Journal of Pragmatics 35(10-11): 15451579.

Cruse A (2000) Meaning in Language: An Introduction to Semantics and Pragmatics. Oxford: Oxford University Press.

Dews S, Kaplan J, Winner E (1995) Why not say it directly? The social functions of irony. Discourse Processes, 19(3): 347-367.

Esslin M (1968) The Theatre of the Absurd. Middlesex: Penguin Books.

Esslin M (1970) The People Wound. London: Methuen \& Co.

Esslin M (1982) Pinter: the playwright. Cambridge: Cambridge University Press.

Gale S (1977) Butter's Going up: A Critical Analysis of Harold Pinter's Work. Durham, N.C.: Duke University Press.

Gibbs R, Izett C (2005) Irony as persuasive communication. In HL Colston, AN Katz (Eds.), Figurative Language Comprehension: Social and Cultural Influences, 131151. Mahwah, New Jersey: Lawrence Erlbaum Associates.

Goffman E (1967) Interaction Ritual: Essays on Face-to-Face Behavior. New York: Doubleday Anchor.

Grice HP (1968) Studies in the Way of Words. Cambridge, Massachusetts: Harvard University Press.

Grice HP (1975) Logic and conversation. In P Cole, JL Morgan (Eds.), Studies in Syntax and Semantics III: Speech Acts, 98-138. New York: Academic Press.

Jaworski A, Coupland N (1999) The Discourse reader. London: Routledge.

Jorgensen J (1996) The functions of sarcastic irony in speech. Journal of Pragmatics 26(5): 613-634.

Kress G, van Leeuwen T (2006) Reading Images: The Grammar of Visual Design. London: Routledge.

Kreuz RJ, Glucksberg S (1989) How to be sarcastic: The echoic reminder theory of' verbal irony. Journal of Experimental Psychology: General 118(4): 374-386.

Kreuz RJ, Long DL, Church MB (1991) On being ironic: Pragmatic and mnemonic implications. Metaphor and Symbolic Activity 6(3): 149-162.

Kumon-Nakamura S, Glucksberg S, Brown M (1995) How about another piece of pie: The allusional pretense theory of discourse irony. Journal of Experimental Psychology: General 124(1): 3-21.

Lakoff G, Johnson M (2003) Metaphors We Live By. Chicago: University of Chicago Press.

Lee CJ, Katz AN (1998) The differential role of ridicule in sarcasm and irony. Metaphor and Symbol 13(1): 1-15.

Leech G (1992) Pragmatic Principles in Shaw's You Never Can Tell. In M Toolan (Eds.), Language, Text and Context: Essays in Stylistics, 259-280. London: Routledge.

Martin J, White P (2005) The language of evaluation: Appraisal in English. New York: Palgrave Macmillan.

Pexman PM, Olineck KM (2002) Understanding irony: How do stereotypes cue speaker intent? Journal of Language and Social Psychology 21(3): 245-274.

Pexman PM, Zvaigne MT (2004) Does irony go better with friends? Metaphor and Symbol 19(2): 143-163.

Pinter H (2002) The Birthday Party and the Room. New York: Grove Press.

Sacks H, Schegloff EA, Jefferson G (1978) A Simplest Systematics for the Organization of Turn Taking in Conversation. In J Schenkein (Eds.), Studies in the Organization of Conversational Interaction, 7-55. New York: Academic Press. 
Sabbagh MA (1999) Communicative intentions and language: evidence from right hemisphere damage and autism. Brain Lang 70(1): 29-69.

Searle JR (1975) Indirect speech acts. In P Cole, JL Morgan (Eds.), Speech Acts, 59-82. New York: Academic Press.

Simpson P (1989) Politeness Phenomena in Ionesco's The Lesson. In R Carter, P Simpson (Eds.) Language, Discourse and Literature, 170-193. London: Routledge.

Sperber D, Wilson D (1981) Irony and the Use-Mention Distinction. In P Cole (Eds.), Radical Pragmatics, 295-318. New York, New York: Academic Press.

Thomas J (1995) Meaning in Interaction: An Introduction to Pragmatics. London: Longman. 


\section{Appendix A: The Three Interrogation Excerpts under Study}

Extract \#1 (20 turns)

1. Goldberg: Webber, what were you doing yesterday?

2. Stanley: Yesterday.

3. Goldberg: And the day before. What did you do the day before that?

4. Stanley: What do you mean?

5. Goldberg: Why are you wasting everybody's time, Webber? Why are you getting in everybody's way?

6. Stanley: Me? What are you

7. Goldberg: I'm telling you, Webber. You're a washout. Why are you getting on everybody's wick? Why are you driving that old lady off her conk?

8. McCann: He likes to do it!

9. Goldberg: Why do you behave so badly, Webber? Why do you force that old man out to play chess?

10. Stanley: Me?

11. Goldberg: Why do you treat that young lady like a leper? She's not the leper, Webber!

12. Stanley: What the

13. Goldberg: What did you wear last night, Webber? Where do you keep your suits?

14. McCann: Why did you leave the organization?

15. Goldberg: What would your old mum say, Webber?

16. McCann: Why did you betray us?

17. Goldberg: You hurt me, Webber. You're playing a dirty game.

18. McCann: That's a Black and Tan fact.

19. Goldberg: Who does he think he is?

20. McCann: Who do you think you are?

(Pinter 2002, Act II, 47-48)

\section{Extract \#2 (20 turns)}

1. Goldberg: Do you recognize an external force?

2. Stanley: What?

3. Goldberg: Do you recognize an external force?

4. McCann: That's the question!

5. Goldberg: Do you recognize an external force, responsible for you, suffering for you?

6. Stanley: It's late.

7. Goldberg: Late! Late enough! When did you last pray?

8. McCann: He's sweating!

9. Goldberg: When did you last pray?

10. McCann: He's sweating!

11. Goldberg: Is the number 846 possible or necessary?

12. Stanley: Neither.

13. Goldberg: Wrong! Is the number 846 possible or necessary?

14. Stanley: Both.

15. Goldberg: Wrong! Why do you think the number 846 is necessarily possible?

16. Stanley: Must be.

17. Goldberg: Wrong! It's only necessarily necessary! We admit possibility only we grant necessity. It is possible because necessary but by no means necessary through possibility. The possibility can only be assumed after the proof of necessity.

18. McCann: Right!

19. Goldberg: Right? Of course right! We're right and you're wrong, Webber, all along the line.

20. McCann: All along the line! 


\section{Extract \#3 (20 turns)}

1. Goldberg: Why did the chicken cross the road?

2. Stanley: He wanted...

3. McCann: He doesn't know. He doesn't know which came first!

4. Goldberg: Which came first?

5. McCann: Chicken? Egg? Which came first?

6. Goldberg and McCann: Which came first? Which came first? Which came first?

7. Stanley [screams]

8. Goldberg: He doesn't know. Do you know your own face?

9. McCann: Wake him up. Stick a needle in his eye.

10. Goldberg: You're a plague, Webber. You're an overthrow.

11. McCann: You're what's left!

12. Goldberg: But we've got the answer for you. We can sterilise you.

13. McCann: What about Drogheda?

14. Goldberg: Your bite is dead. Only your pong is left.

15. McCann: You betrayed our land.

16. Goldberg: You betray our breed.

17. McCann: Who are you, Webber?

18. Goldberg: What makes you think you exist?

19. McCann: You're dead.

20. Goldberg: You're dead. You can't live, you can't think, you can't love. You're dead. You're a plague gone bad. There is no juice in you. You're nothing but an odour!

(Pinter 2002, Act II, 51-52) 
